\title{
Poner la diferencia en escena: Entrevista a Alberto Lomnitz
}

\section{Rocío Galicia}

Alberto Lomnitz: Director, traductor, dramaturgo, actor, docente y funcionario teatral. Nació en Chile, pero desde los diez años es ciudadano mexicano. Estudió actuación, dirección e improvisación en el Terry Shreiber Studio de Nueva York. En la Universidad de Illinois en Chicago obtuvo la maestría en Comunicación y Teatro. Su trayectoria resulta ejemplar por la multiplicidad de actividades que ha desempeñado $\mathrm{y}$, ante todo, por el compromiso que ha asumido con el teatro. En 1993 fundó la compañía Seña y Verbo: Teatro de Sordos, con la cual ha obtenido diversos premios y realizado numerosas giras nacionales e internacionales. Entre 1998 y el año 2000 fue Coordinador Nacional de Teatro. Un rasgo significativo en la trayectoria de Lomnitz ha sido su interés por difundir textos importantes de la dramaturgia universal a través de traducciones. Es miembro fundador de la Liga Mexicana de Improvisación y codirector artístico - junto con Boris Schoemann - de la Compañía Titular de Teatro de la Universidad Veracruzana.

Su más reciente trabajo con Seña y Verbo ¿¿Quién te entiende?!, es la concreción de un teatro que posibilita el diálogo entre dos códigos: la lengua de sordos y el lenguaje escénico. Las obras de Seña y Verbo están arraigadas a la comunidad de sordos, no obstante, desde su fundación el objetivo ha sido producir un teatro de calidad para los circuitos teatrales. Única en su tipo en América Latina, esta compañía se define como una asociación artística y educativa. ¿¿Quién te entiende?! es la consolidación actoral de un grupo de actores sordos, la depuración de un lenguaje propio y es sobre todo la necesidad de compartir el universo cotidiano de una minoría. El texto es significativo porque resuena en quienes no imaginamos la vida desde esa posición. Recientemente esta obra tuvo una temporada exitosa en La Sala Xavier Villaurrutia de la Ciudad de México. 
Procedes de una familia de destacados cientificos, tus padres obtuvieron cada uno en su disciplina nada menos que el Premio Nacional de Ciencias, máximo reconocimiento que se otorga en México.

Así es, además mi hermano Jorge murió a los 39 años siendo un científico brillante. Ahora en el Instituto de Física de la UNAM hay un premio en dinámica no lineal que se llama Jorge Lomnitz. Mi hermano Claudio es Full Professor en la Universidad de Columbia, es un antropólogo e historiador muy reconocido a nivel internacional. $\mathrm{Mi}$ abuelo fue científico, en fin, desciendo

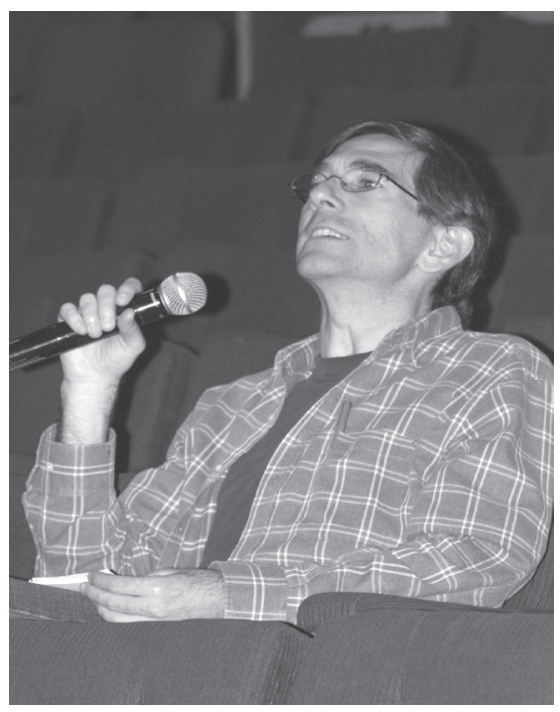

Lomnitz dirigiendo. Foto: Luz Mastache de una familia consagrada a la ciencia.

Tú obtuviste el mejor promedio de tu carrera, te hubieras dedicado a la ciencia de no haberse atravesado el teatro en tu camino.

Sí. Estudié Investigación Biomédica Básica, es una carrera muy selecta. Todo iba bien hasta que tuve una crisis personal, en esa época pensé que era zapatero, hijo de zapateros... Sentí que iba siguiendo la línea que me había trazado el destino y quise romper y andar un camino propio. Ahora me interesa más el teatro que la ciencia. Sin embargo, siento que simplemente cambié el tema de estudio: dejé los hongos filamentosos y empecé a estudiar el comportamiento humano. Pero muchas personas dicen que sigo teniendo un enfoque científico, yo lo siento así algunas veces.

Después de esa decisión, ¿cómo llegaste a la conformación de una compañia de teatro de sordos?

Fueron una serie de casualidades las que me encaminaron hacia allá. Trabajé con el National Theatre of the Deaf, vinieron a México a hacer una gira y me contrataron a la distancia como actor vocal. En realidad tuvimos poco tiempo para ensayar porque su vuelo se retrasó, pero en cuanto bajaron del avión toda su atención la pusieron en mí porque sabían que si el actor vocal fallaba la función se podía venir abajo, ya que el actor vocal es quien liga la función con el público oyente. En el ensayo que tuvimos se sorprendieron 
porque me sabía todo. Había ensayado teniendo como referencia los videos que me enviaron de la puesta. Desde ahí me los gané. El hablar con señas me fascinó, aprendí durante la gira la Lengua de Señas Americana. Me sedujo la cultura de los sordos, el lenguaje, su forma de socializar y, por supuesto, las posibilidades artísticas de hacer teatro con señas. A nivel humano lo que me atrapó es que cuando hablas con sordos te miran a los ojos y no despegan la mirada porque se corta la comunicación. Entre sordos se miran a los ojos y con la vista periférica ven las manos, lo más importante para ellos está en los ojos, tienen una forma de comunicación muy intensa. Además al comunicarte con la cara, con las manos, con el cuerpo es imposible tener un habla inexpresiva. Para los sordos la emotividad es parte del lenguaje, si la suprimes no hay comunicación. Es increíble hacer teatro así. Cuando terminó la gira sentí que mi vida había cambiado radicalmente. Tiempo después National Theatre of the Deaf me becó para ir a estudiar con ellos. A mi regreso a México el paso natural fue fundar una compañía de teatro de sordos. Así surgió Seña y Verbo. Primero aprendí señas americanas y luego la Lengua de Señas Mexicana.

El trabajo de Seña y Verbo es político, ¿estás de acuerdo?

Sí, es una compañía política. Mientras yo iba tratando de entender quiénes eran los sordos, cuál era su situación y su lucha, la compañía fue adquiriendo un discurso político. ¿¿Quién te entiende?! es una obra que resume no sólo la parte plástica y artística que a mí me interesa, ahí emerge también un teatro político. Yo nunca he sido una persona vinculada a la política, no me atrae para nada, pero Seña y Verbo me dio la posibilidad de hacer teatro político. Fue un regalo porque no fue algo buscado. Creo que es un trabajo de resonancia importante no sólo para los sordos. Nos llaman para participar en foros donde interesa desencadenar discusiones sobre tolerancia y diversidad. No me parece una casualidad que yo haya acabado atraído por ese tipo de teatro si consideramos mi historia personal. Lo digo porque yo como toda mi familia fuimos marcados por el exilio, por los viajes, los cambios de país y por una sensación de ser de afuera, de estar entre distintas culturas. La experiencia de vivir en varios países te hace consciente de la diversidad cultural. Lo bilingüe ha sido una exploración que me caracteriza como artista, pues también he hecho trabajo bilingüe inglés-español. Monté en Nueva York una obra sobre moros y cristianos para conmemorar el Quinto Centenario: el Encuentro de Dos Mundos. Fue muy interesante montar una obra sobre diversidad cultural nada menos que en Nueva York. También he traducido varias obras. Me atrae todo lo que es bicultural, ya sea sordo-oyente o México-Estados Unidos. Naturalmente me 


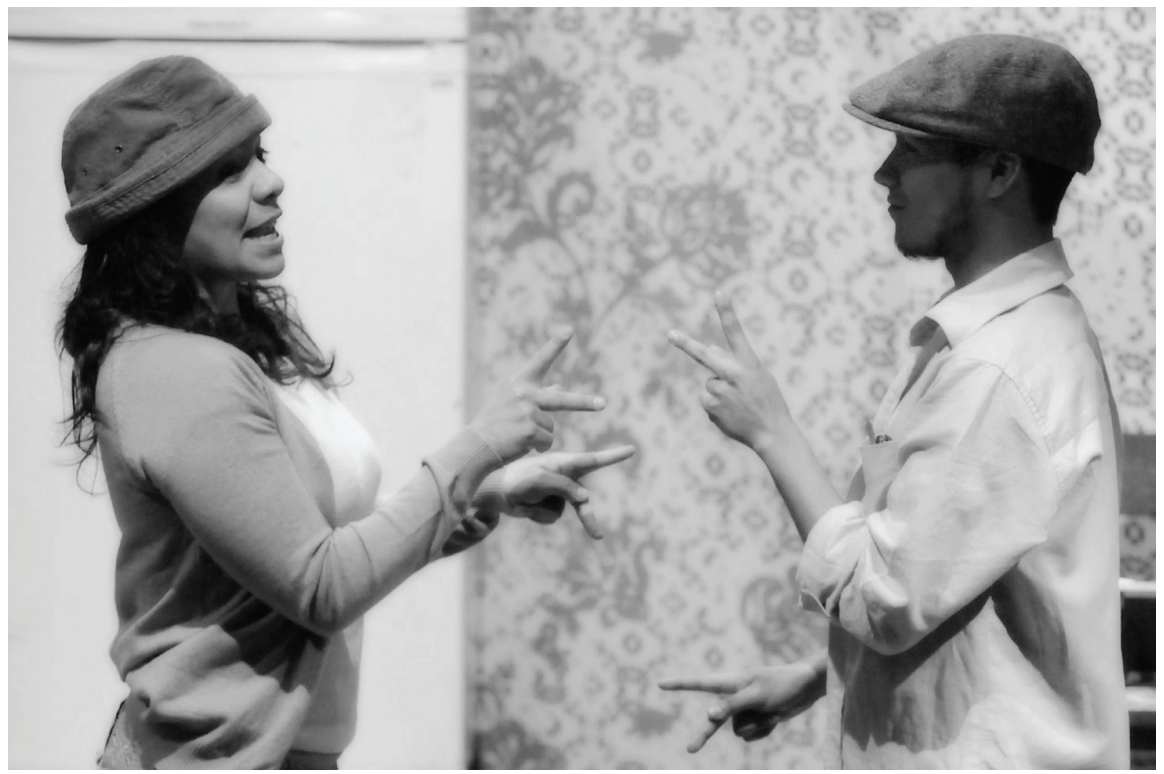

¿¿Quién te entiende?! Foto: José Jorge Carreón

fui encaminando a algo que traigo en las entrañas. Con los sordos es muy interesante porque siempre me ha gustado viajar y con ellos viajas muy lejos sin tener que salir de esta ciudad. La cultura de los sordos es una cultura muy distante.

Por referencias externas al teatro supe que el movimiento de sordos en México no se entendería sin Seña y Verbo.

Sí y lo mismo pasa con otros grupos de teatro en otros países. Si revisas la historia de los sordos en Estados Unidos verás que no se puede entender el movimiento de sordos sin el teatro. Si tú ves libros de historia de la sordera en el siglo XX, te vas a encontrar que le dedican por lo menos un capítulo al Teatro Nacional de los Sordos de Estados Unidos, ninguno omite mencionarlo. En México Seña y Verbo ha jugado un papel importante en el movimiento de sordos. Llegamos en un momento crucial. Yo traía la visión del teatro para sordos en Estados Unidos, pero cuando llegué a México no podía creer lo que pasaba. Cuando empecé a traer a los artistas sordos de Estados Unidos, ellos decían: "Siento que me fui como 30 años atrás." No exageraban. El primer cambio de mentalidad por la lucha de los sordos, la necesidad de defender su lenguaje se dio en Estados Unidos a principios de los años 60 y aquí a finales de los 90. Es increíble darse cuenta que en México 
ha habido una resistencia del establishment. Hace poco un grupo de sordos levantó una demanda en la Comisión Nacional de Derechos Humanos contra la Secretaría de Educación Pública. Se acusó a la SEP por la violación de los derechos humanos de esta comunidad. La nueva ley general de discapacidad reconoce el derecho del sordo a una educación bilingüe y la SEP se resiste a implementarla. La resistencia del establishment educativo y médico en México es impresionante. Hay gente que se sorprende porque caricaturizamos a los médicos en las obras, pero no es así. En ¡¿Quién te entiende?! el médico dice: "Sí oye, pero es flojo." Ese texto, ¿sabes quién nos lo dijo? Todos. Todos los actores sordos de Seña y Verbo dijeron: "Eso decía mi médico." Es una experiencia compartida por todos los sordos. Los médicos dicen: "El paciente no está colaborando. No quiere usar el aparato auditivo." Resulta asombroso, pero todo lo que te pueda contar es poco. Ha sido muy interesante poder participar en la lucha de los sordos.

Un logro de Seña y Verbo es haber formado espectadores. Hay un público sordo y otro oyente que sigue a esta compañia.

Sí. El rey que no oía, pero escuchaba fue un exitazo de taquilla, llenamos el Teatro Orientación en una temporada de seis meses. Dentro de la barra infantil del Instituto Nacional Bellas Artes El rey que no oía, pero escuchaba ha sido de los grandes éxitos. A esta obra asistieron pocos sordos, pero obtuvimos un lugar destacado en el teatro para niños. Seña y Verbo tiene mucho público infantil, se nos llenan las funciones. El público reconoce en Seña y Verbo a un grupo de teatro para niños. En teatro para adultos no ha sido tan fácil. ¿¿Quién te entiende?! fue una sorpresa en ese sentido porque tuvo un arrastre increíble. Atrajo a muchos sordos. Nunca una obra había impactado así a esa comunidad. A ellos les encantó aunque es una obra para los oyentes, es una obra didáctica, pero a los sordos les fascinaba. Comentaban: "Hasta que alguien lo dijo. Eso es lo que hemos estado tratando de decir." Con las historias de esta obra los sordos se identifican, nos dimos cuenta que son tres historias representativas. Muchos sordos llevaron a sus familiares para que vieran lo que viven ellos.

Lei que para conformar este texto te basaste en los testimonios de sordos, pero hacer de ese material un discurso teatral debió ser un trabajo complicado.

Fue un trabajo arduo porque teníamos quince horas de material grabado ya seleccionado. Darle una coherencia fue difícil. Había que tomar decisiones, opté por centrarme en la niñez. La obra lo que muestra son los primeros años, etapa fundamental donde se da la adquisición del lenguaje. En 


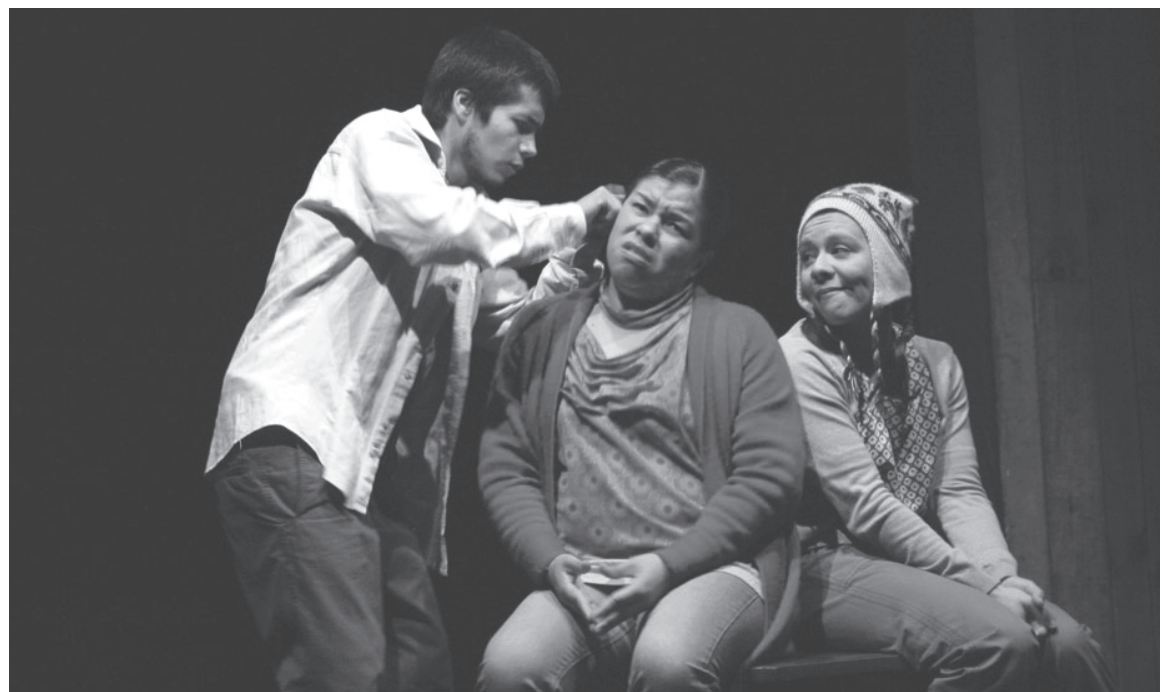

¿¿Quién te entiende?! Foto: Ricardo Esquerra

la obra hay mucho humor porque así son ellos, yo no lo inventé. El humor es un rasgo característico de la diferencia. Los sordos se burlan de su condición, poder reírte de lo que eres te permite enfrentarte a situaciones muy adversas. Siempre ha sido así entre las personas marginadas. Los chistes que se cuentan en la comunidad judía sobre el holocausto son tremendos. En México tenemos chistes sobre la explosión en San Juanico, el terremoto de 1985 o las circunstancias económicas. Esa es una manera de lidiar con lo tremendo. Los sordos lo hacen constantemente, el humor de la obra es de ellos.

Alberto, ¿cuál es tu próximo proyecto teatral?

En septiembre estrenaré en el Teatro Helénico Verónica en portada de Estela Leñero, se trata de una comedia de enredos donde personajes del teatro y el mundo editorial enlazan sus vidas por medio de las sábanas. ${ }^{1}$.La obra es un retrato muy agudo de la clase media. Hace veintiún años puse en escena Casa llena también de esta dramaturga.

Centro Nacional de Investigación Teatral “Rodolfo Usigli,” México

Note

Después de la entrevista, Verónica en portada se estrenó. Véase la página 173 para más información. 